Tmmediately following an earthquake, emergency managers must make quick response decisions using limited information. Automatically and rapidly generated computer maps of the intensity of ground shaking (ShakeMaps) are now available for California within about 10 minutes of an earthquake. This quick, accurate, and important information can aid in making the most effective use of emergency-response resources.

\section{What is ShakeMap?}

ShakeMap is a tool used to portray the extent of potentially damaging shaking following an earthquake. It can be found on the Internet at http://earthquake.usgs.gov/shakemap/ and is automatically generated for both small and large earthquakes in areas where it is available. It can be used for emergency response, loss estimation, and public information. ShakeMap was first developed for earthquakes in southern California as part of the TriNet Project, a joint effort by the U.S. Geological Survey (USGS), California Institute of Technology (Caltech), and the California Geological Survey (CGS).

Following the Northridge earthquake in 1994, older analog instruments were replaced with a state-of-the-art seismic network with digital communications in real time. Deployment was completed in 2002. This network enables seismic data to be used in new and innovative ways. A product of the new network, ShakeMap, was made possible by advances in telecommunications and computer-processing speed, and research aimed at understanding the relation between recorded ground motions and damage intensities. ShakeMaps show the distribution of ground shaking in the region, information critical for emergencymanagement decision-making. It is the distribution of intensity (local severity of shaking), rather than the magnitude (the total energy released

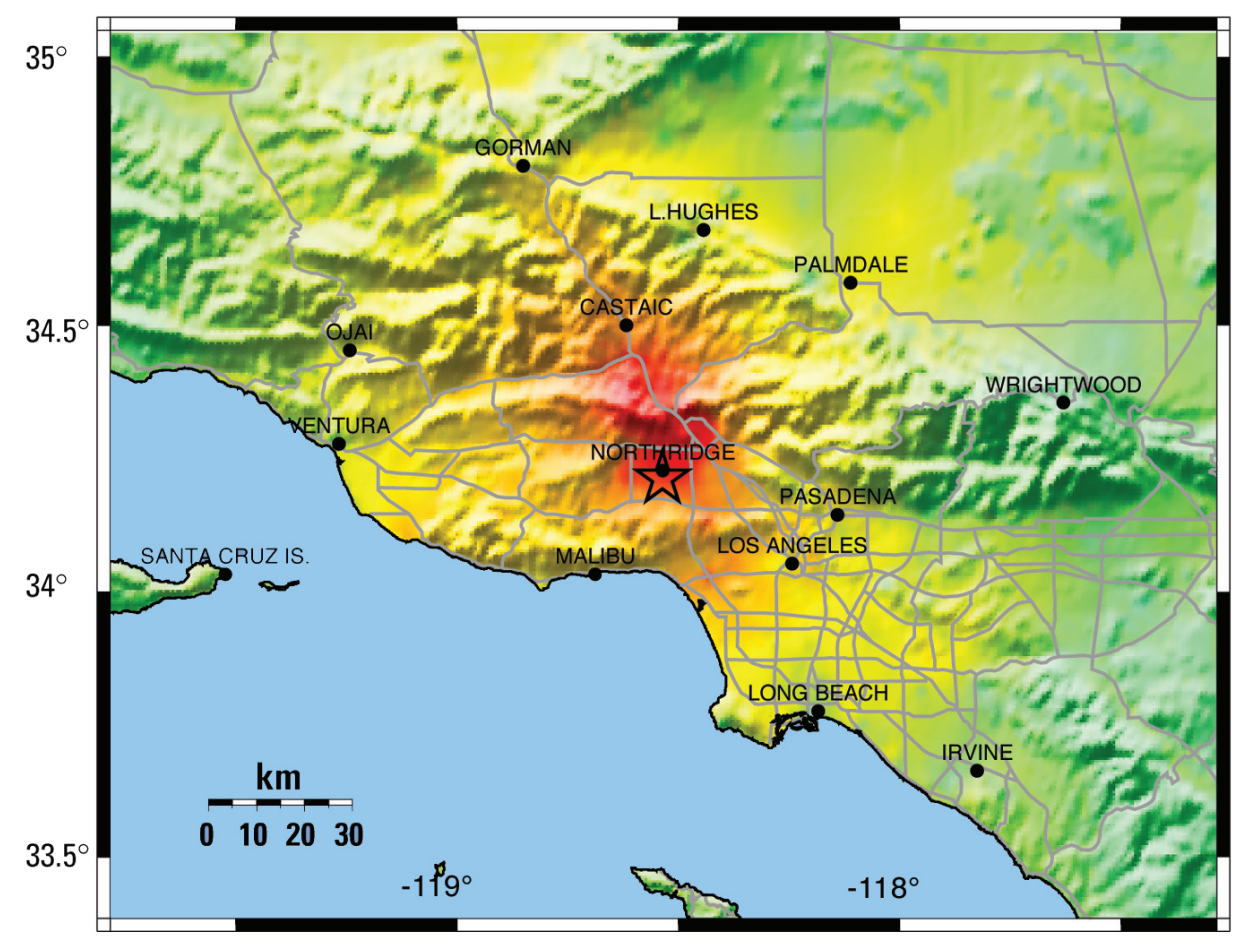

\begin{tabular}{|c|c|c|c|c|c|c|c|c|c|}
\hline $\begin{array}{l}\text { PERCEIVED } \\
\text { SHAKING }\end{array}$ & Not felt & Weak & Light & Moderate & Strong & Very strong & Severe & Violent & Extreme \\
\hline $\begin{array}{l}\text { POTENTIAL } \\
\text { DAMAGE }\end{array}$ & none & none & none & Very light & Light & Moderate & Moderate/Heavy & Heavy & Very Heavy \\
\hline PEAK ACC.(\%g) & $<.17$ & $.17-14$ & $1.4-39$ & 3.9-92 & $9.2-18$ & $18-34$ & $34-65$ & $65-124$ & $>124$ \\
\hline PEAK VEL.(cm/s) & $<0.1$ & $0.1-1.1$ & $1.1-3.4$ & $3.4-8.1$ & $8.1-16$ & $16-31$ & $31-60$ & $60-116$ & $>116$ \\
\hline $\begin{array}{c}\text { INSTRUMENTAL } \\
\text { INTENSITY }\end{array}$ & I & II-III & IV & V & VI & VII & VIII & IX & $X+$ \\
\hline
\end{tabular}

If only they had been available. . . ShakeMaps did not exist in 1994 when the magnitude 6.7 Northridge, Calif., earthquake occurred. Had a ShakeMap been available for that earthquake, it could have been used to rapidly guide emergency-response teams to areas that potentially had the greatest need. The above ShakeMap is made with data recorded from the Northridge earthquake. It shows that the greatest shaking occurred to the north of the epicenter and in other isolated areas, a pattern that could not have been anticipated with only magnitude and location information for the earthquake.

by the earthquake), that provides useful information about areas prone to damage. Having this information in real time will result in lives saved and reductions in property damage.

\section{Why ShakeMap is Necessary}

After a damaging earthquake, emergency managers must quickly find answers to important questions: Where is the most serious damage? 


\section{Making ShakeMap}

\author{
1 The shaking level is \\ recorded at hundreds \\ of seismic stations \\ (triangles). In the areas \\ between stations, shaking \\ levels are estimated on \\ the basis of knowledge \\ of how seismic energy \\ travels and of the local \\ geology. Relatively weak \\ soils that transmit seismic \\ energy more easily are \\ shown in orange, yellow, \\ and red. Stronger units are \\ shown in green and blue.
}
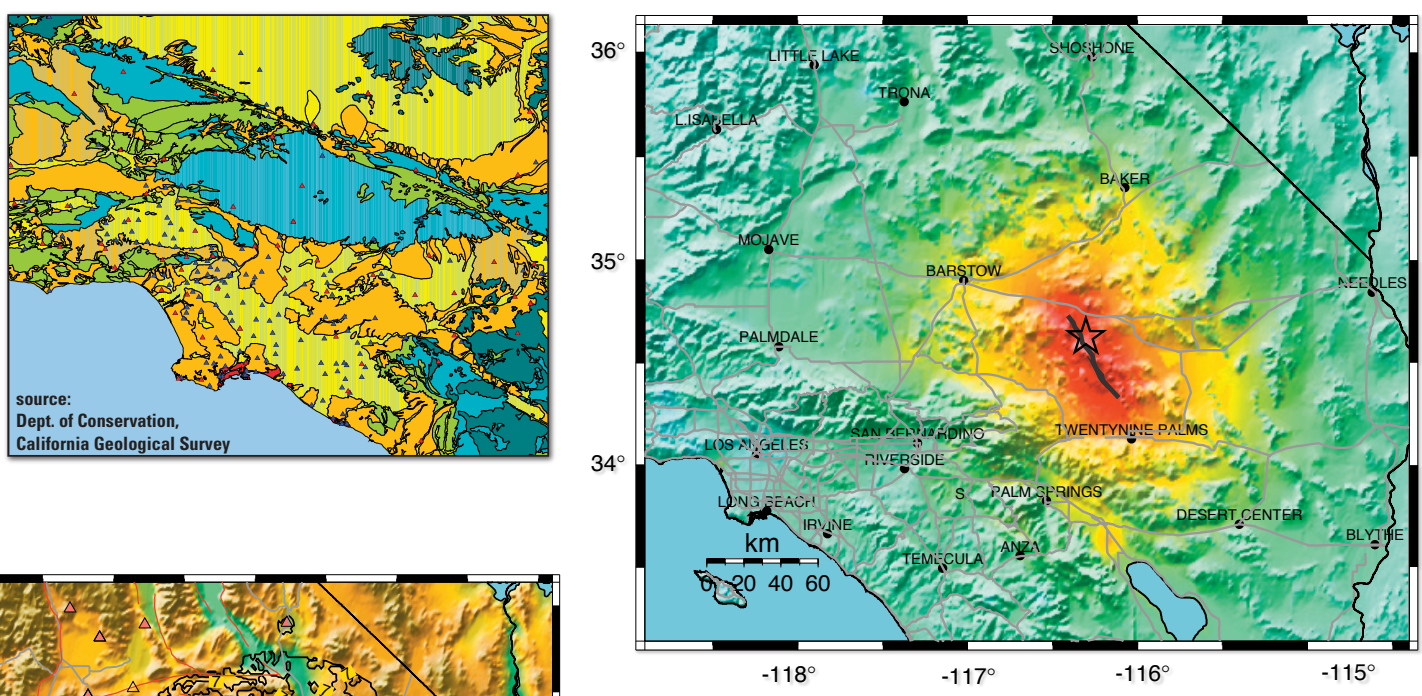

3 Ground motions are converted to color-coded seismic intensity to show potential damage and perceived shaking level at all locations. Additional maps provide information on specific frequencies of shaking waves, that can be used to anticipate the response of different types of buildings to the ground motion. These are useful for estimating which areas are most likely to have damaged buildings and utility and transportation lifelines. All the maps are refined and updated as more data become available.

and yellows indicate higher elevation, blues and greens indicate lower elevation).

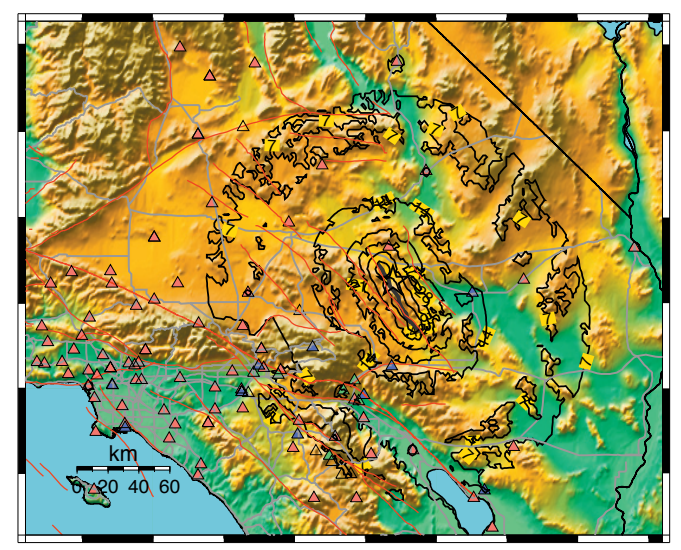

\section{Putting ShakeMap to Use}

Where is less damage? What resources must be mobilized and in what quantities? Government response organizations typically answer these questions after a preliminary survey of the damaged area. Private-sector organizations conduct their own investigations but also wait for government reports regarding damage. This reconnaissance requires hours and sometimes days to complete. As a result, decisions regarding search and rescue, medical emergency response, care and shelter for the injured and displaced persons, and other critical response needs must often be made while information is still incomplete.

In the past, rapidly available information on an earthquake included the magnitude, location, and some assessment of the probability of damaging aftershocks. Even though useful, this information was not sufficient to support rapid post- earthquake emergency-management decision-making. Because an earthquake happens over a fault surface, not at a single point, the location of the earthquake (the epicenter) tells us only where the earthquake started, not necessarily where the shaking was the greatest. For a large earthquake, damage can sometimes occur hundreds of miles from the epicenter. Other factors, such as rupture direction and local geology, influence the amount of shaking in a particular area.

Although emergency responders identified many areas of heavy damage soon after both the 1994 Northridge and the 1989 Loma Prieta earthquakes in California, additional regions of severe damage were only belatedly discovered. A ShakeMap displays the distribution of ground shaking within minutes after an earthquake so that emergency services may be deployed to those locations.
ShakeMap's rapid portrayal of shaking distribution following an earthquake provides opportunities to enhance post-disaster response by integrating other useful technologies including geographic information systems (GIS) and the Federal Emergency Management Agency's (FEMA) loss-estimation software (HAZUS). City, county, and State agencies can obtain ShakeMap "shapefiles" for use as overlays with GIS, providing a more detailed understanding of potential damage to local infrastructure and facilitating a more effective response. HAZUS estimates economic (damage and dollar losses) and societal impacts (number of casualties, displaced families, shelter needs) of earthquakes. The California Office of Emergency Services uses ShakeMap rather than magnitude and location to calculate HAZUS loss estimates, thus generating estimates based on actual measured ground shaking. 
Response and recovery efforts by utilities and private companies benefit from quick knowledge of where facilities are likely to be damaged, and which employees may be unavailable due to the location of their homes or commuting routes with respect to damaged areas.

Using ShakeMap, the California Department of Transportation (Caltrans) will evaluate traffic flow and prioritize inspection of the nearly
25,000 bridges and overpasses statewide, and earthquake engineers will prioritize building-safety inspections, an otherwise potentially overwhelming task. The public will also have access to the information needed to understand their situation, or to gauge the severity of the shaking in communities where relatives reside.

ShakeMaps are organized in a database and made available on the World Wide Web. The maps are interactive- selection of an individual station on the map displays detailed information, including the station name, geographic coordinates, and the local peak groundmotion values. The Web site provides access not only to maps of the most recent earthquakes but also to maps of significant events in the past and shaking expected for candidate earthquake ruptures in the future-so called "scenario" earthquakes.

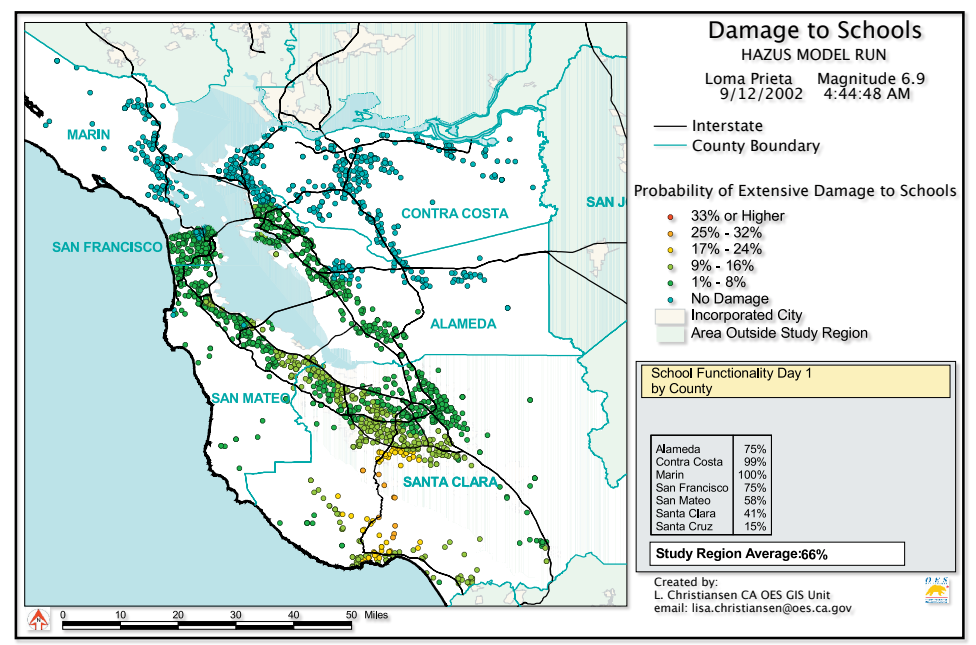

Likelihood of Damage to Schools. Scenerio map for an earthquake similar to the 1989 magnitude 6.9 Loma Prieta, Calif., earthquake, prepared using a geographic information system (GIS). This map was made by using ShakeMap input for Hazards U.S. (HAZUS) lossestimation software. Probable damage to schools is just one of many HAZUS maps produced to help evaluate and respond rapidly following a damaging earthquake. The Federal Emergency Management Agency (FEMA), statewide agencies, and local municipalities also use HAZUS to plan their response to earthquake disasters. Figure courtesy of L. Christensen, California Governor's Office of Emergency Services (OES).

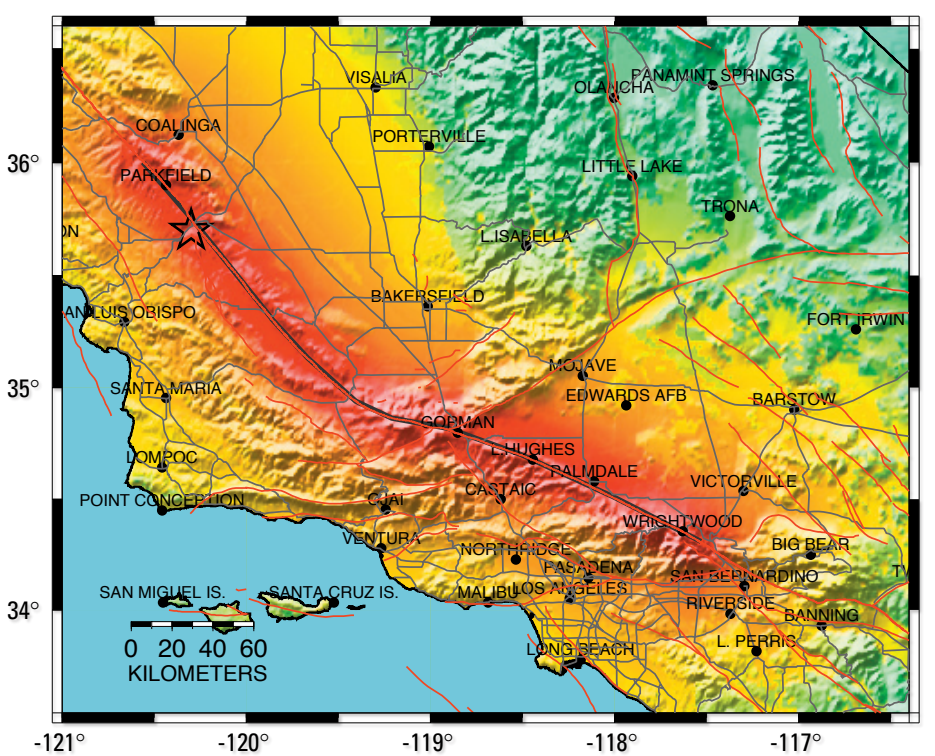

1857 Scenario. "Scenario" ShakeMap for a hypothetical repeat of the magnitude 7.8, 1857 Fort Tejon earthquake in southern California. Strong, potentially damaging shaking occurred as far as 200 miles from the epicenter (star) over a significant portion of the State. The most severe shaking occurred near a portion of the San Andreas fault that ruptured (black trace). Color scale is the same as that of the Northridge ShakeMap.
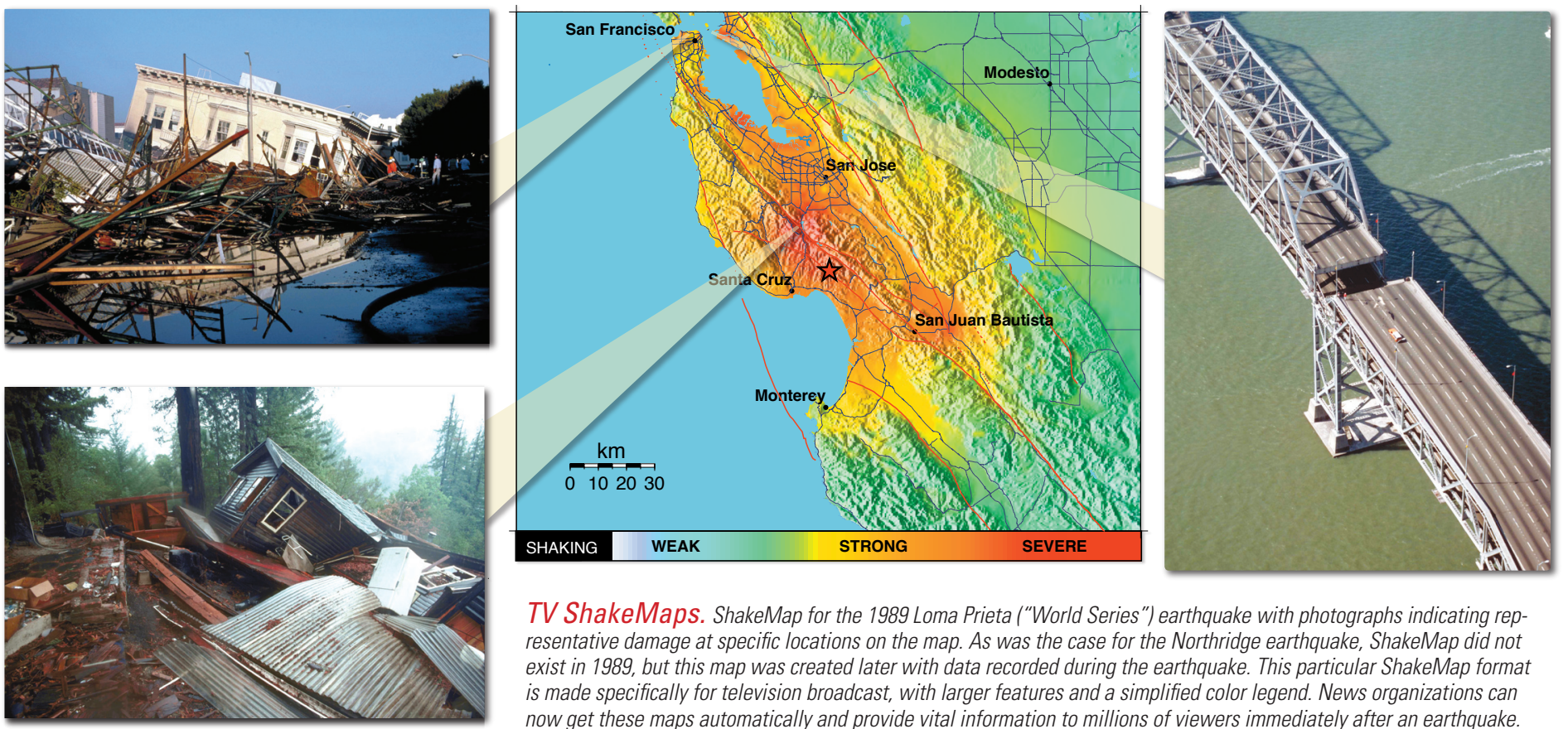

TV ShakeMaps. ShakeMap for the 1989 Loma Prieta ("World Series") earthquake with photographs indicating representative damage at specific locations on the map. As was the case for the Northridge earthquake, ShakeMap did not exist in 1989, but this map was created later with data recorded during the earthquake. This particular ShakeMap format is made specifically for television broadcast, with larger features and a simplified color legend. News organizations can now get these maps automatically and provide vital information to millions of viewers immediately after an earthquake. 


\section{Northridge (M 6.7) versus Nisqually (M 6.8)}

Comparison of ShakeMaps generated for the magnitude 6.7, 1994 Northridge, Calif., and the magnitude 6.8, 2001 Nisqually, Wash., earthquakes. Though similar in magnitude the difference in earthquake focal depth resulted in substantially different levels of shaking and damage and, therefore, necessitated very different levels of emergency response. Such differences are not obvious from the magnitude and epicenter information alone but are readily discernable from these displays.

Modified Mercalli Intensity Scale Intensity describes the effects of ground shaking on people, buildings, and natural features. It varies from place to place within the affected region, depending on the location of the observer with respect to the earthquake epicenter. In general, the intensity decreases as one moves away from the fault, but other factors such as rupture direction and local geology also influence the amount of shaking. Roman numerals are commonly used to describe intensities to distinguish them from magnitudes. The Modified Mercalli Intensity Scale is currently used in the United States and ranges from I to $X$.

\section{Magnitude Scale}

Magnitude is a number representing the total amount of energy released by the earthquake source. It is based on the amplitude of the earthquake waves recorded on instruments that have a common calibration. The magnitude of an earthquake is thus represented by a single, instrumentally determined value.

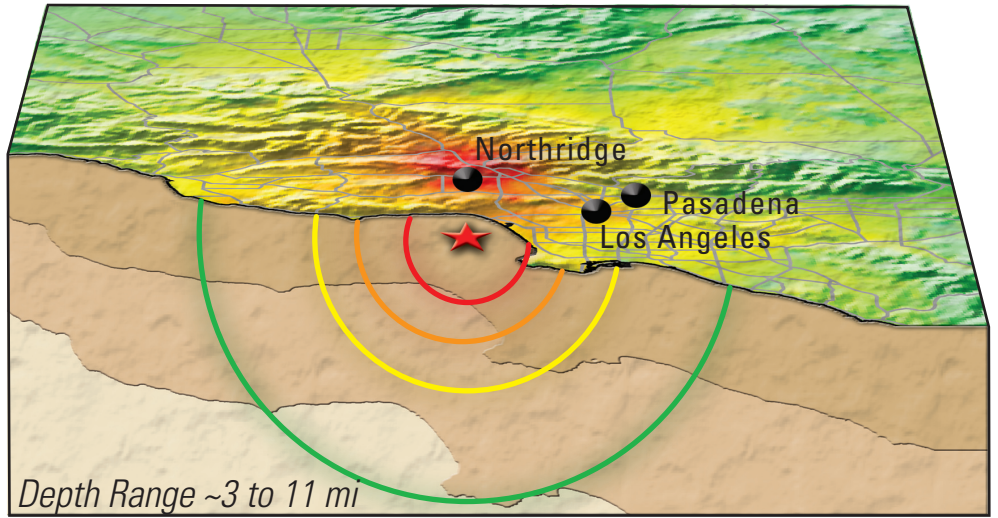

Northridge

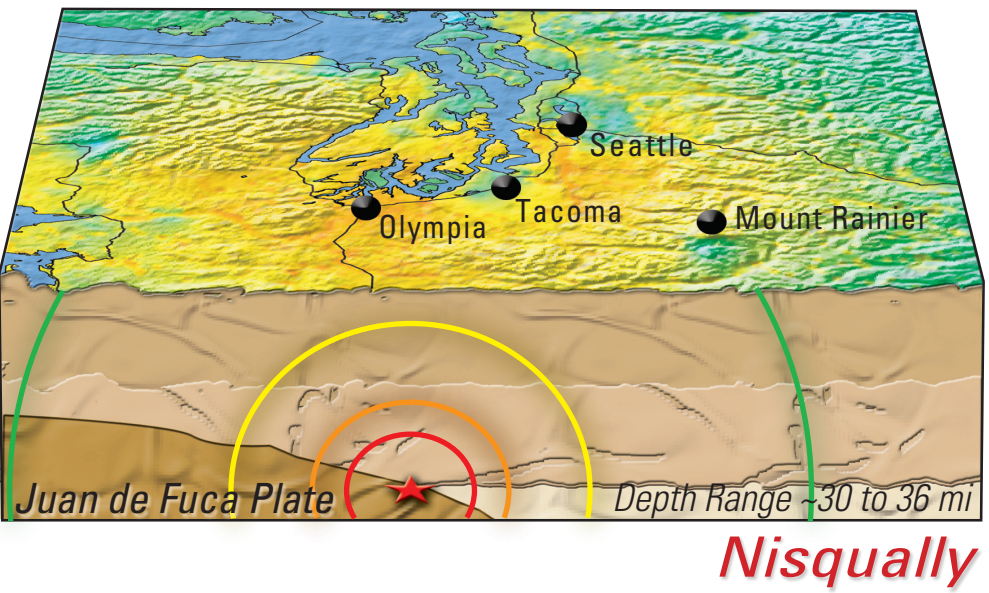

Depth (in miles) $0-15$ $15-30$ below 30

Despite the similar magnitudes, the shaking intensity of the Northridge earthquake reached IX (very strong) close to the epicenter (note the red shading near Northridge), but only reached VII for the deeper Nisqually event (note the lack of red shading).

\section{The Future of ShakeMaps}

Current work will soon enable users to have automatic delivery of a wide range of ShakeMap products with a variety of types of telemetry, including wireless devices. Coupling automatic ShakeMap delivery with instant analysis of the user's facilities will allow immediate impact assessments, enabling rapid response decisions to be made more easily and confidently.

Efforts are now underway to expand the use of ShakeMaps to other seismically active areas of the United States under the auspices of the U.S. Geological Survey's Advanced National Seismic System (ANSS, http://earthquake.usgs.gov/). In addition to California, ShakeMaps are now being produced in other seismically active urban areas, including Seattle and Salt Lake City. With expanded seismic instrumentation, it will eventually be possible for any seismic network to generate groundshaking maps for its region and make them rapidly available on the Internet and through the media. An investment in high-quality instrumentation and ongoing support can result in a system that will promote more efficient emergency response, help reduce losses, and save lives after an earthquake. The work of U.S. Geological Survey scientists within ANSS is only part of the ongoing USGS effort to safeguard lives and property from future earthquakes.
For More Information Contact:

Earthquake Hazards Program

U.S. Geological Survey

Golden, C0 80401

ShakeMaps are at:

http://earthquake.usgs.gov/shakemap/

Partners: Cooperating Regional Networks under the Advanced National Seismic System (ANSS), including the California Integrated Seismic Network (CISN), the University of Utah Seismographic Stations (UUSS), and the Pacific Northwest Seismic Network (PNSN).

Written by David Wald, Lisa Wald, Bruce Worden, and Jim Goltz

Graphics and layout design by Lisa Wald and Eleanor M. Omdahl

This Fact Sheet is available online at http://pubs.usgs.gov/fs/fs-087-03/ 